DOI https://doi.org/10.18551/rjoas.2018-04.09

\title{
WORK STRESS (CAUSES, IMPACTS AND SOLUTIONS): A CASE STUDY ON THE NET. YOGYAKARTA EMPLOYEES
}

\author{
Wardhana Andhika Kusuma \\ Universitas Islam Indonesia Yogyakarta, Indonesia \\ E-mail: dhika asli@yahoo.com \\ ORCID: 0000-0001-8827-2139
}

\begin{abstract}
The purpose of this research is to know the causes of the emergence of the stress, and the impact or effects that appear due to stress. The results of research show the factors triggering the emergence of stress: demands and high work pressure; work overload; the inter-personal relationship (including disputes with colleagues); buildup of work; overtime; disagreements among the leadership; lack of appreciation from superiors; complexity of the work; the lack of help from colleagues and superiors; and the discipline of the time.
\end{abstract}

\section{Key words}

Stress, impact, stress solutions, media workers.

The media industry is currently very rapidly in Indonesia after the reform era, even often seen as offsetting amongst the people. In addition to rewarding in terms of the economy, the media industry is also useful as a place to work for the people and industries of television, often involving the workforce in large numbers. This is certainly very helpful to relieve the Government's burden in terms of unemployment (Hidayat and Prakosa, 1997).

Mass media emerged as a highly influential force. The submission of information through the mass media such as newspapers, television, radio, and movies have shaped human knowledge and opinions regarding various events or things that concern people's lives. The mass media has been present at every moment of our lives regardless of time and distance even the presence of the mass media can affect a person's behavior and way of life. Among the various mass media, television media is media that is effective in forwarding the message. Information, news and entertainment media content is a highly anticipated television audience, because television media can accommodate your needs and provide a variety of information, (Severin and Tankard, 2001).

In the world of work, including in the media industry, there is the possibility of emerging issues with respect to the work and the conditions that can trigger the appearance of stress. Either consciously or not, the work that person does, like a job in the production section of the program or in the news (journalist) as well as administrative and financial work in office, potentially inflicting stress on him. For example, the burden of work and the deadline of the superior overload or under load work, and others. It can appear in the span of a short or long, because people dabbling in the workplace of more than eight hours per day.

Information is currently a need that is very important and cannot be separated from human life. The curiosity is human nature became the biggest driving factor will be such a need. Man looking for information for a variety of purposes of life. In addition to adding to the knowledge that can broaden the horizon of thinking, information also serves as one of the considerations in decision making (Hidayat \& Prakosa, 1997).

In the world of work, including in the media industry, there is the possibility of emerging issues with respect to the work and the conditions that can trigger the appearance of stress. Either consciously or not, the work that person does, like a job in the production section of the program or in the news (journalist) as well as administrative and financial work in office, potentially inflicting stress on him. For example, the burden of work and the deadline of the superior, overload or underload work, and others. It can appear in the span of a short or long, because people dabbling in the workplace of more than eight hours per day. 
A study mentions three of 10 journalists suffered post-traumatic stress disorder (PTSD) after working in dangerous tasks, depression, anxiety, and problems in interpersonal relationships also were reported. The research is supported by the discovery of Feinstein dkk (2002) who found that nearly 30 percent of reporters stationed in conflict areas show signs of post-traumatic stress. The profession of journalist also has a high safety risk threat. Many of the events that befell reporters covering news in the area of conflict, as in natural RCTI Reporter Ersa Siregar was killed in a firefight between TNI with GAM in the Peureulak area of NAD in 2003. Other problems also add to the workload of reporters is the low level of wellbeing. The final results of the Research Alliance of independent journalists (AJI) about the welfare of journalists still shows low levels of income of journalists. Research done in the 17 cities reveal the average earnings of journalists between Rp 900,000,-to Rp 1.4 million per month. But the sad thing is still a reporter found his salary under Rp 200,000 per month.

Based on data from the National Institute of Occupational Health and Safety (NIOSH) in 2010 , there are around $40 \%$ of workers reported that their work is very stressful; the next $25 \%$ are they view their jobs as the main sources of stress in their lives; and $75 \%$ of workers believe that the job is now more stressful compared to previous employment; $29 \%$ of workers feel very stress at work; and the last of the $26 \%$ of workers said that "I quite often or very often felt saturated or feel stress against her work." This data simply open our view that this adult work stress have become important issues in the world of work that if allowed to happen will be able to affect the quality of life of many people, both in terms of productivity of work or personal life. More than $25 \%$ "often" or "always" experience stress, $8 \%$ of people "always" experience stress, whereas $5 \%$ "never" experienced stress, at least it was said to be the speaker.

While the facts of the International Labour Organization (ILO) revealed that about $10 \%$ of workers are experiencing depression, stress and anxiety in the United States, United Kingdom, Germany and Finland. In Finland, there are $50 \%$ of workers reported signs of stress. In the United Kingdom, 3 out of 10 workers are experiencing mental disorders due to work.

Before discussing further, first we need to understand what the meaning of stress in the eyes of the researchers and what things that trigger the appearance of stress. The term stress is seen as a response to common and non-specific to any physiological or psychological demands emanating from neither outside nor within him, it is called a stressor. The stress is experienced when a situation perceived or judged to exceed the abilities or resources. Psychological stress is a relationship between the individual and the environment that are valued by individuals exceeding the abilities or resources that it owns and threatens the well-being of the individual.

Sources of stress or stressor can equal or different in each individual, depending on how the individual perceive it. Many previous studies which find out what are the stresor in the world of work. Life is full of potential, namely stressor incident or situation and the changes in life that produces stress, (Lazarus, 1995). Approach to Life Events proved that changes in one's self whether good or bad, can trigger the appearance of stress. The importance of cognitive assessment in response to stress and the everyday job turns out can produce stress. According to her everyday stress though are light but are accumulative and eventually become a source of stress that weight.

Stress basically can be divided into two, namely "eustress good stress/" (stress) and "bad stress/distress " (negative stress or bad). We know that stress is not good for your health, especially if too much. But as it turns out, too little is also not ideal. Research tells us that a little stress is good for your health and is not always bad. This is called with the "good stress/eustress". Is Eustress that really motivate you and help you move on. This usually occurs during the period of transition to better things; You may get a big promotion at work; Could a baby have come into your life; Maybe you moved into your dream home or; It is possible that all your dreams come true and a stranger who you have never met is thinking you are a pretty good writer and you've received your first publishing contract. These are all examples of the extraordinary events of the long-awaited, but also events that can cause the 
body to become exhausted. Our body does not know the difference between distress and eustress.

In addition, work stress is more often associated with the emergence of health complaints compared with financial problems or family problems. The total costs that must be incurred related to the health and productivity of employees who are experiencing the stress of work in America is estimated at $\$ 50-\$ 150$ billion per year. Forty percent of the turn-over of employees caused by work stress, and experts predict the company will have to pay $150 \%$ of salaries for new hires replacement employees who resigned due to work stress.

\section{LITERATURE REVIEW}

Stress is the result of transactions between individuals with their environment. Stress cannot be generated from the individual or from its surroundings, but rather from the interaction between the two. The stress is experienced when a situation perceived or judged to exceed the abilities or resources. Psychological stress is a relationship between the individual and the environment that are valued by individuals exceeding the abilities or resources that it owns and threatens the well-being of the individual.

According to Soewondo (2010), there is no definition of stress are common. Understanding the stress depends on what approach will be used. Stress can sometimes be seen as a stimulus or trigger a response, or the interaction between the individual and the environment. The concept of stress as the stimulus is described as a stimulus in the environment faced by individuals and is considered disruptive. This is as it has been submitted, i.e. events that threaten such as hurricanes, plague, the death of the family, and others.

The concept is the next stress is seen as a process of transactional relationships, not to mention as a stimulus or just a response only. According to Soewondo (2010), eustress is a good or positive stress, for example as an achievement of the meaning, and then fall in love, as well as won the game. However, if the stressor is unwanted then cannot be managed properly then it can lead to distress or stress the negative and potentially triggers the appearance of stress. Distress is a negative stress, for example, is less or excessive stimulation, bored, tired, exhausted, the demands are too high, and excessive workload.

Lazarus and Folkman's (1984) in Soewondo (2010) explain that psychological stress is a relationship between an individual with the environment that will be perceived exceeds the ability of its own and threatens the well-being of individuals such. Here is a model of stress from Lazarus and Folkman:

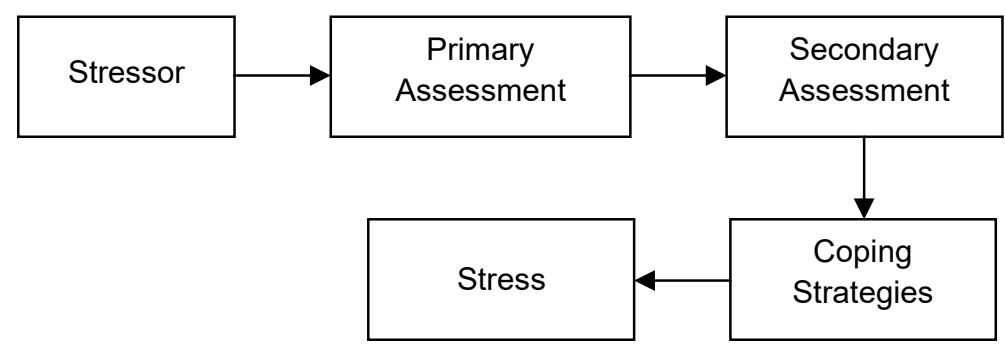

Figure 1 - Model Stress Lazarus and Folkman, 1984 (quoted from Soewondo, 2010)

In this model introduced the term coping, coping with itself is a process where individuals try to manage the perceived gap between the demands of origin of individuals or the environment with existing capabilities in the face of stress. A coping is a cognitive and behavioral efforts that keep changing to specifically manage the demands of a heavy or exceeds the ability of the person. Coping with emotions and can focus on the problem. In coping with the focus on individual emotions, trying to reduce the negative emotions or reactions to relieve the pressure of the emotions evoked by stressor in a way, avoid releasing emotions, relax, or blame yourself. Coping will only focus on the problem, and 
thereafter was to resolve the issue, look for associated information, and then perform an action directly, change your mindset or viewpoints and motivation, or make a new plan.

In this model introduced the term coping, coping with itself is a process where individuals try to manage the perceived gap between the demands of origin of individuals or the environment with existing capabilities in the face of stress. A coping is a cognitive and behavioral effort that keep changing to specifically manage the demands of a heavy or exceeds the ability of the person.

Coping with emotions and can focus on the problem. In coping with the focus on individual emotions, trying to reduce the negative emotions or reactions to relieve the pressure of the emotions evoked by stressor in a way, avoid releasing emotions, relax, or blame yourself. Coping will only focus on the problem, and thereafter was to resolve the issue, look for associated information, and then perform an action directly, change your mindset or viewpoints and motivation, or make a new plan. According to Davis, Eshelman and M'Kay (2008), there are four sources of stress in General, namely:

- Environment that demands a person to be able to adjust to that individual. We have always claimed to be able to adjust itself against noise, air pollution, weather, traffic density, etc.

- Social Stressor, for example such demands will be the time and the requirement to give full attention towards it, in the job interview, and specifies a priority which will be made in advance in the work, presentation work, personal conflicts, financial problems and lost/the death of someone we love and care about.

- Physiological Stressor. Can be described as rapid growth in children adolescents, menopause in women, lack of exercise, the less nutrition, less time sleeping, the emergence of diseases, injuries, and aging can occur in all people. Physiological reaction of this kind is our response to the environment and threats as well as social changes can trigger stress symptoms such as muscle tension, headaches, abdominal pain, anxiety and depression.

- Sources of stress from the mind. Our brains are always interpreting the complex changes to the body, the environment, and we need to know when the right time to provide a response to the emergence of the trigger source of stress. And also how we can label and interpret what we're facing and what we will face in the days to come may make us experience stress or we can also feel relaxed. For example, as I interpret the arrival of tops to your desk, because you feel blundered in the job given to you then will be able to bring up a response to anxiety, fear, and tense. However, if you interpret it as mediocre, then stress response itself will not appear.

The combination of a variety of stressor (stressor in the workplace and outside work) can lead to tension or stress, affect morale and lowering the quality of work. Effects of stress will be more felt on workers aged over 45 . Work stress can decrease the performance of your workforce and increase the turn-over of employees in the company, (Suls and Martin, 2005). Work stress can reduce a person's concentration, lower productivity, an increase in the frequency of errors in work, high rates of injury on the job, the high level of attendance and irritability as well as increase conflicts with co-workers and supervisors. Someone who was in a situation of distress often feels faster emotions, and the emotions are often tipped with unpleasant. Weiten et al. (2009) mentioned the response of the usual negative emotions appear is as follows:

- Temper: Stress often lead to anger and intensitasnya ranging from mild to uncontrolled angrily.

- Anxious: this can be caused because of the pressure to present themselves, the threat that frustrating, or uncertainties associated with changes in the situation.

- Sad: Sometimes the problem is a frustrating stress this can also cause a person grieving.

Could not complete the work that has been given by its leader, can cause a person to feel guilty, while death and divorce can also cause a very deep sadness. However there is just someone who can also feel more positive emotions in stressful situations and emotions 
that can improve one's endurance in the face of stress. As already explained, stress often gives rise to a very strong emotional reactions. The response cause physiological changes. Though when a person undergoes stress, then we will soon realize that our heart beat faster, and a little difficult to draw breath, and sweating more than usual. The emotional and physiological response to stress tend to occur directly and cannot be predicted. While the other is a big part of response behaviors include coping with which refers to active efforts to control, reduce, or tolerate the demands arising from stress, (Quick et al, 2013).

Stress management is a skill that allows one to anticipate, prevent, manage, and recover from the stress of the perceived threat due to threats and incompetence in coping with (Smith, 2002). Emotion management techniques such as meditation, yoga, is progressive relaxation; techniques to manage a better lifestyle with sports, eat regular and healthy, or do not consume alcohol or cigarettes; as well as the techniques done to address aspects of behavior such as time management. There are four approaches to stress of work, namely:

- Approach through meditation; This approach needs to be done to the way employees are concentrated to the natural mind, relaxes muscular work, and calming emotions. This meditation can do for $15-20$ minutes. Regular meditation is done in a special room. A Muslim employee regular Dzuhur prayers after doing so through prayer and remembrance to Almighty God.

- Approaches social support; This approach is done through activities that aim at providing social satisfaction to employees. For example: play games and joked.

- Approach Through Biofeedback; This approach is carried out through medical guidance. Through the guidance of physicians, psychiatrists, and psychologists, so expect employees can eliminate the stress that had befallen him.

- Approach to personal health; This preventive approach is the approach before the onset of stress. In this case the employees in continuous periods of health check, do the muscle relaxation, nutrition, and exercise settings regularly.

Detecting the causes of stress and reaction form, then there are three patterns in coping with stress, including:

- Harmonious Pattern; Harmonious pattern is a pattern deal with stress with the ability to manage time and harmoniously and does not give rise to a variety of obstacles. With this pattern, the individual is able to control various preoccupations and challenges with how to set the time on a regular basis. The individual is always the face of the task exactly, and if he needs to delegate certain tasks to others by giving full confidence. Thus, the harmony and balance between the pressure that is received with the given reaction. Likewise against the harmony between himself and his environment.

- Healthy Patterns; Healthy pattern is a pattern deal with stress the best IE with the ability to manage behavior and actions so that the presence of stress does not cause the disorder, but will become more healthy and growing. Those who belong to this group are usually able to manage time and busy life in a good way and regularly so it does not need to feel there is something pressing, although the actual challenges and pressures.

- Pathological Patterns; Pathological patterns is the pattern facing stress with various disorders impacting physical or social-psychological. In this pattern, the individual will face numerous challenges in ways that do not have the ability to manage tasks and regularity and time. In this way may give rise to dangerous reactions because it can cause a variety of problems.

\section{METHODS OF RESEARCH}

The methods used in this research was the qualitative approach with descriptive analysis method, a design that gives it easy for researchers to record, monitor and follow the process of an event or activity of an organization as it is in a certain time brackets and further 
on to interpret the research problem to answer. The method was chosen because it allows doing research and gathering information about the sources of stress in depth and comprehensive. As explained by Locke, Spriduso and Silferman in Creswell (1994:147): "Qualitative research is interpretative research. The US is such the blases, values and judgement of the researches become explicity stated in the research report. Such openness is considered to be useful and positive, "while the descriptive analysis, a method is a method used to describe or analyze a research results but is not used for make wider conclusions" (Taylor et al., 2015).

Research Instrument; in qualitative research, which became the instrument or research tool is the researchers themselves so researchers must be "validated". Validation against the researchers, include; understanding qualitative research methods, mastering insights against a field that is examined, the readiness of the researchers to tap into the object of research, both academically as well as logically. Qualitative researchers as a human instrument function sets the focus of the research, selecting informants as a data source, perform data gathering, assessing data quality, data analysis, interpret the data and make conclusions upon his findings. The subject of the research is the ones that will be made for canvassed by researchers. The object of the research is the place will be used as research or who became the focus of a research. In this research that became the subject of research is the 10 employees of the NET. and its object is located in the NET. Yogyakarta.

Determination of the Informant; Informant in research is the person or the perpetrator who really know and control problems, as well as get involved directly with the research issues. By using qualitative research methods, then the researcher is closely associated with contextual factors, so in this case the sampling is made as much information from various sources. The intent of both of the informant is to multiply the information that formed the basis of the theory of design and construction. In qualitative research, it is becoming a major consideration in data collection is the selection of informants. In qualitative research does not use the term population. The sampling technique used by researchers is a purposive sample. Purposive sample is the technique of determination of samples with specific considerations, (Patton, 2005).

Qualitative research does not question the number of informants, but it could depend on whether or not the right selection key informant, the diversity and the complexity of social phenomena are examined. Thus, the informant is determined by the technique of snowball sampling, which is the process of determining the informant upon previous informant without specifying the amount for sure with digging up the research topic related information required. Search the informant will be discontinued after the research information was considered adequate already. As for the criteria of the determination of the key Informants (key informants), in the giving of information and data that is precise and accurate regarding stress management on several journalists NET. These. The informant was needed in research this is the employee's NET. Yogyakarta, which consists of 10 journalists and divided into 6 journalists male and 4 female reporter.

The technique of data collection was the way researchers to obtain data in a research. Because this research is qualitative research then the data obtained must be deep, clear, and specific. Data collection can be obtained at one of the results of observation, interview and combined/triangulation. Data is information about the something object of research that put more emphasis on this aspect of the matter, everything that is only associated with the description of a fact which is found researchers on site research.

Data Analysis Techniques; Qualitative data analysis is an attempt made by way of working with data, organizing data, categorize it into a unit that can be managed, process, looking for and find patterns, find what is important and what is learned, and decide what can be told to others, (Miles et al., 2013). Based on the definition above it can be concluded that the initial steps of data analysis is collecting the data, compiled systematically, then presented the results of his research to other people. The stage of the analysis of qualitative data is as follows:

- Read/study the data, marking the key words and ideas that exist in the data.

- Learn key words of it, attempting to find themes that originate from the data. 
- Renders the ' model ' was found.

- Coding has been done.

Data analysis starts by conducting in-depth interviews with key informants, namely someone who really understand and know the situation the object of research. After conducting interviews, analysis begins by creating a transcript of the interview, with the way the play back the recording of the results of the interview, listen carefully, and then write down the words that are heard in accordance with what is record such. After the researchers wrote the interview results into the transcript, then researchers should read carefully and then do the reduction of data. Researchers make the reduction of data by creating abstraction, i.e. take and record information-useful information in accordance with the context of research or ignore words that need not be so obtained the gist of wording only, but the language matches the language informants.

The abstraction that was made in the form of units which are then classified based on taxonomy of domain research. Domain analysis is gaining public and thorough description of the object/research or social situations. Researchers obtained this domain with questions how to do grand and minitour. Meanwhile, a domain is very important for researchers, because as a foothold for further research. Regarding the analysis of the taxonomy that is by selecting a domain and then spelled out into more detail, so that its internal structure can be known.

Data Reduction (Reduction Of Data); Data reduction is not a thing apart from the analysis. Data reduction is defined as the process of selection, concentration on simplification, and transformation of data emerging from rough notes written in the field. Data reduction activities take place continually, especially during the qualitative-oriented projects underway or during data collection. During data collection, reduction, i.e. stages occur make a summary, encode, browse the theme, making cluster-cluster, create the partition, and writing memos. Data reduction is a form of analysis that sharp, classify, direct, dispose, and organize data in such a way so that conclusions can be drawn and verification final. Data reduction or transformation process continued steadily after field research, to complete the final report is composed. So in qualitative

research can be simplified and transformed in various ways: through strict selection, through the summary or description, classified in a wider pattern, and so on.

Data Display (Presenting Data); At this stage, researchers developed a description of organised information to draw conclusions and taking action. The presentation of the data is often used in this research is a form of narrative text. The intention of the text is a narrative description of the information that researchers have been classified previously regarding the perception of about the performance of librarians who later formed conclusions and further the conclusions presented in text form narrative.

Conclusion/Verying (Withdrawal Of The Summary); Researchers trying to draw conclusions and verify by looking for the meaning of any symptoms of acquired from the field, record the regularity and the configuration that may exist, plot of causality phenomenon and proportions. At this stage, the authors draw conclusions from data that has been inferred before, and then match the notes and observations made at the time of the author's research.

\section{RESULTS OF STUDY}

The NET. Yogyakarta is the representative office of NET Mediatama, based in Jakarta, and the NET. Yogyakarta's own new stand for one more year. The number of employees who became the subject of the study amounted to 10 people.

And here is the result of a summary of the sources of stress (stressor) obtained from the results of the interview of the source: Demands and high job pressure; Overload of work; inter-personal Relationship (including disputes with colleagues); The backlog of work; Overtime; Depth-leadership; Lack of appreciation of the leadership; the complexity of the work; The lack of help from colleagues and leadership; Discipline of the time. 
Table 1 - Subjects description

\begin{tabular}{|c|c|}
\hline Subject & Subject \\
\hline $\begin{array}{l}\text { A- The Demands And High Work Pressure } \\
\text { - Overtime } \\
\text { - Lack Of Sleep } \\
\text { - Anxious } \\
\text { - Less Comfortable } \\
\text { - Sensitive } \\
\text { - Prayer } \\
\text { - Drinking Coffee } \\
\text { - Sharing With Friends }\end{array}$ & $\begin{array}{l}\text { B • Overload Of Work } \\
\text { - Inter-Personal Relationship } \\
\text { - Anxious } \\
\text { - Less Comfortable } \\
\text { - Lazy Entered Work } \\
\text { - Prayer } \\
\text { - Sharing With Friends } \\
\text { - Leave Work }\end{array}$ \\
\hline $\begin{array}{l}\text { C. Salary Does Not Match } \\
\text { - Demands And High Work Pressure } \\
\text { - Fatigue } \\
\text { - Sharing With Friends }\end{array}$ & $\begin{array}{l}\text { D. Overload Of Work } \\
\text { - Demands And High Work Pressure } \\
\text { - Incoming Lazy Work } \\
\text { - Does The Spirit Of Work } \\
\text { - Sports } \\
\text { - Leave Work }\end{array}$ \\
\hline $\begin{array}{l}\text { E - Inter-Personal Relationship } \\
\text { - Headaches } \\
\text { - Does The Spirit Of Work } \\
\text { - Lazy Entered Work } \\
\text { - Prayer } \\
\text { - Watch Television }\end{array}$ & $\begin{array}{l}\text { F - Depth-Leadership } \\
\text { - Discipline } \\
\text { - Time Anxious } \\
\text { - Fatigue } \\
\text { - Sharing With Friends Or Through } \\
\text { Social Media }\end{array}$ \\
\hline $\begin{array}{l}\text { G- The Demands And High Work Pressure } \\
\text { - Lack Of Appreciation } \\
\text { - Anxious } \\
\text { - Shortness Of Breath Chest } \\
\text { - Want To Upset } \\
\text { - Sharing With Friends } \\
\text { - Do His Personal Hobby }\end{array}$ & $\begin{array}{l}\text { H・ Lack Of Help From Colleagues } \\
\text { And Leadership } \\
\text { - Overload Of Work } \\
\text { - The Demands And Pressure Of } \\
\text { Work } \\
\text { - Headache } \\
\text { - A Work Furlough }\end{array}$ \\
\hline $\begin{array}{l}\text { 1. Demands And High Work Pressure } \\
\text { - Depth-Leadership } \\
\text { - Discipline } \\
\text { - Time Anxious } \\
\text { - Headache } \\
\text { - With Family } \\
\text { - Shopping Cart }\end{array}$ & $\begin{array}{l}\text { J - Depth-Leadership } \\
\text { - Demands And High Work } \\
\text { Pressure } \\
\text { - Discipline } \\
\text { - Lazy Time Entry Work } \\
\text { - No Smoking } \\
\text { - Working Spirit } \\
\text { - Listening To Music } \\
\text { - Rest At Home }\end{array}$ \\
\hline
\end{tabular}

Sources of stress are also resulted in the appearance of the impact or effects to the health of the employee's NET. Yogyakarta, either psychologically or physically impaired person. The following is the impact/effects of the stress inflicted upon the results of the interview against the subject: The tense atmosphere; Feeling uncomfortable; Easily fatigued; Anxiety; Easy sensitive; Lack of sleep; Saturation; The headache; Lazy work entry; Spirit of the work.

And of all explanations of factors trigger the appearance of stress and the effects that appear due to stress this, here is the solution they (the subject) are doing at the time of the stress: Sports; Serve the Lord; Chat with Family; Shopping; Play With Friend; Drink coffee; Time off Work; Sleep; Watch TV.

\section{DISCUSSION OF RESULTS}

The result of this research shows that 10 of the subject has trigger the emergence of sources of stress (stressor) works in an environment that could potentially cause the stress on themselves. High job demands became one of the many sources of stress mentioned by the subject. When deciding to join a company, of course, the work is routine stuff that should be done by everyone, no exception by the employees NET. However, sometimes the given work demands exceed the ability of someone to do it, and finally came the stress.

The source of the stress normally arises from external factors, ranging from the environment in which they work, as well as employee relations with superiors, and a sure source of stress that may arise from this type of work or the burden of his work. As is the case in this study which addresses the issue of work stress experienced by the employee's NET, after conducting an analysis of the sources of stress that appear on the employee's $\mathrm{NET}$, then later the virtue of 10 sources of stress that exists in some the employee is. Among 
them are the following: demands and high work pressure; Work overload; The inter-personal relationship (including disputes with colleagues); Buildup of work; Overtime; DepthChairman; Lack of appreciation of the leadership; Complexity of the work; The lack of help from colleagues and leadership; and the discipline of the time.

Be employees working in the world of television is indeed to be ready with the risks that can lead to the appearance of stress, let alone working for a news division. Reporter spearheading from news coverage in the media, they are required to keep on hand for 24 hours and even they should be ready to be sent on duty wherever it (including assigned should be ready in the conflict-prone), not to mention coupled with the risk of losing a life when in charge of covering something dangerous.

Workers in the retail sector that is in Jaipur India have problems the stress that arises from their workload is high. From the journal authors can conclude that the workload can be a source of stress, and that the results are then equal to what the author found on NET some employees of Yogyakarta that workload too heavy resulting in a sense of stress that interferes with the activities and lives of individuals.

The work has a high workload and time pressure (deadline) high make individuals feel pressured and stressful (Davis \& Newstrom, 1989). If the workload is too high, the work hours of pressing and the job containing high risk is a factor that can cause stress. The profession of journalist also had a pretty tight competition, while the presses that can accommodate such professionals have very small amounts. Journalists are not able to convey information to the Office as soon as possible and because the news does not appear in the media where he worked the next day would be at risk of losing his job. This is because the newspapers they will contain news items not actual so that in the end will be left readers. If the workload is too high, the work hours of pressing and the job containing high risk is a factor that can cause stress.

Journalists can be categorized into a job that has a high work stress levels because of the workload, the working time and the risk of insistence that high. Zaenuddin (2007), suggests that journalists must be able to work under pressure. This is related to the problem of the time. Journalists should be prepared to work under time pressure. That is, the work of the journalist both in its status as a reporter or editor it is always limited by time.

Some of the effects arising out of employee stress on NET, such effects will indeed vary in each individual. Not all subjects will feel the same effect with other subjects, there are some subjects experience health disorders (ranging from headaches, lack of sleep, dizziness) or interference on the side of his psychic (such as easy-sensitive, feeling uncomfortable). The effect of the stress this again varies for each individual, not all people experience the same interference with findings from researchers about work stress on the employee's NET. The stress here is a little annoying in the life of the subject, such as sleep deprivation. When a subject does not have enough time to sleep, it is then that occurs is the domino effect against his work, it has not been coupled with factors trigger stress which will appear in the Office.

Indeed the effect of the stress that arises almost most of the attack on a person's health, the effect will be felt directly (e.g., headaches, and dizziness). Not to mention it will appear an inefficient provision in relation with its surroundings, a sense of stress or frustration this will be something that Scotch on someone. Such feelings of irritability, this effect will also make connections with surrounding disturbed. The combination of a variety of stressor (stressor in the workplace and outside work) can lead to tension or stress, affect morale and lowering the quality of work. Work stress can reduce a person's concentration, lower productivity, an increase in the frequency of errors in work, high rates of injury on the job, the high level of attendance and irritability as well as increase conflicts with co-workers and supervisors.

Stress increases when bosses or co-workers socially become insensitive to the needs of others or demean others and too critical of the work produced by others. In addition, employees will experience stress if he felt unappreciated by others or feel no progress in his work. Plus more if they don't get the recognition or promotion work from companies that they believe that they deserve it. The question of factors trigger the appearance of stress and its 
effects on the performance of employees. This stress will bring up various side effects such as: impaired health, lifestyle, personal lives of employees. And it will also have an effect on performance as well as their commitment. In this journal then obtained the results that trigger stress due to low wages, excess workload, competition with fellow employees, management, low support factors (appreciation), work environment, a long working time, knowledge the target is low, high, and it's all have implications for performance negatively to work.

The previous description can describe how and what they feel is natural as well as working in the world of television, and almost all of them experience problems similar to stress triggers them. Well that's a factor of pressure, and the complexity of the work that they do, they are almost the same complain how the attitudes of Jakarta (Jakarta NET) in their work. Working as an employee of the media especially television is indeed to be ready with all their risks. Risks such as overtime, salaries are not appropriate (subjective), pressure is a matter of preaching, not to mention individual issues like relations inter-personal which the emergence of saturated taste, a sense of tired, until eventually led to the stress itself.

Stress management is a skill that allows one to anticipate, prevent, manage, and recover from stress because of the perceived threat and incompetence in coping with that done (Smith, 2002). Techniques of stress management techniques in this very much. Many of the things they do to get out of those situations, some of them seeking ways with sports, there are also later serve the Lord. The majority answered they would be main or do their hobbies when finished off the job, and even though it was only a temporary effect but simply help them to forget about the existing problems in the Office. Personal health approach is the approach before the onset of stress. In this case the employees in continuous periods of health check, do the muscle relaxation, nutrition, and exercise settings regularly.

Stress not only seen as a negative phenomenon that is permanent, but there is a positive side as well. Therefore, stress management is required to minimize the impact of this stress. There are several ways that can be done by the company to reduce the stress on employees, for example, is conduct an effective training and family gathering. In addition to the demands of the job, the working relationship with fellow co-workers or superiors also became one of the sources of stress for some employees of the NET. As is known, the working relationship with fellow co-workers or superiors not forever walking in accordance with desire. Often it appeared wrong in the work if it is not resolved can lead to strife and eventually gave rise to stress.

Based on the results of the interview to its subject, the disharmony in the leadership have taken small decisions and a lack of help from superiors while facing problems of work became one of the causes of the emergence of misunderstandings and disputes with tops on the NET. For example, from the results of the interview subject is aware that some feel the lack of discipline in terms of the time at their internship in work and difficult it is to set up a child apprentice to be able to do his job properly. It is a source of stress for those who can certainly affect relations inter-personal with kids their fruits, either in work or in private life. If you have this, they will be more prone to work stress, especially coupled with job demands that exceed the demands of the work of the sons of his apprenticeship and working pressure from their supervisors.

In addition, employees will experience stress if he felt unappreciated by others or feel no progress in his work. Plus more if they don't get the recognition or promotion work from companies that they believe that they deserve it. Similarly, according to according to Soewondo (2010) that identifies personal inter-relationships, either with fellow co-workers or superiors as one source of stress. Research results Soewondo (2010) is appropriate depends on the results of research on the tenth of this subject.

Based on the results of the interview, the subject undergoes physical complaints as well as mental stress. Dizziness, headaches and tightness in your chest is the physical complaints that are often experienced. In addition there is also a perceived mental complaints, such as feeling anxious, feeling lazy work or not in the mood to work, avoid any tops or avoid prosecution work that ultimately makes their stress and not to enter work or take a leave of absence a couple of days for refreshing with the family or just rest at home. This is in accordance with some expert opinion about the effects of work stress. According to 
Soewondo (2010), the effects of stress are physical disorders such as heart palpitations, migraines, high blood pressure, sweating, aching heart; such a change in attitude, and withdrew, feeling depressed, timid. While according to Lazarus (1993), in Weiten et al. (2009), the response of the usual negative emotions appear due to stress is feeling anxious. Anxiety can be caused by the pressure to present themselves, the threat of which make for frustrating, or uncertainties related to changes in the situation. The effects of work stress are mentioned by Soewondo and Lazarus appeared in ten subjects of research.

Work stress can reduce a person's concentration, lower productivity, an increase in the frequency of errors in work, high rates of injury on the job, the high level of attendance and irritability as well as increase conflict with colleagues. The effects of work stress also appears on the subject, although none of them who decided to resign from the NET, but the existence of an intention to not go work on the next day became one of the indications of the inconvenience of working that does not cover the possibility it could lead to a decision to resign from the NET.

The conclusions of the source of the stress of appearing on 10 employees NET Yogyakarta of which is as follows: demands and high work pressure; Work overload; The inter-personal relationship (including disputes with colleagues); Buildup of work; Overtime; Depth-Chairman; Lack of appreciation of the leadership; Complexity of the work; The lack of help from colleagues and leadership; and the discipline of the time. Be employees working in the world of television is indeed to be ready with the risks that can lead to the appearance of stress, let alone working for a news division. Reporter spearheading from news coverage in the media, they are required to keep on hand for 24 hours and even they should be ready to be sent on duty wherever it (including assigned should be ready in the conflict-prone), not to mention coupled with the risk of losing a life when in charge of covering something dangerous.

In a conversation at the time of the interview against the subject matter then found some complaints of this workload. Those who work in television, complained that most of the workload they have received already outrageously heavy, often then the workload that can even be torturing myself once. Finally, any work that it must have to individually-san-typical of that of the good functioning of its work as well as the burden of his work. Like other journalists, perhaps not just journalists who feel a high load, but other similar jobs felt the burden of his work. For example, those who work as employees of the hospital, in the traffic police force, or even friends who worked in the factory as workers, they also have the burden of work and sources of stress.

Be employees of a television is indeed required to be ready whenever and wherever she is placed, not even that coverage task is rarely life threatening. It is become part of life in the television employees, especially those who work in the Division of news coverage or journalists. The requirement to always be ready and not had their working time which is not infrequently lead to the emergence of the stress, they are required to always timely sending of news, they are required to always "zero mistake" when working, not to mention the risk cannot be assembled with the family when the important moments.

As for the effects of the perceived work stress on the tenth of the subject was physical disorders such as a sense of tightness in your chest, dizziness and headaches; a change in attitude as avoiding tops or avoid work; changes in behavior such as could not be concentration; and attendance. The effects appear more inclined to attack physically impaired, such as dizziness and headaches. That's because a high job demands and should soon be completed, a high workloads well confiscated their thoughts and energy. The television broadcasting media is different to others, because television is a medium that shows the visual and audio simultaneously. Therefore, any broadcast quality to look fine. It is to be one of the factors why the television employees should work without error and pay attention to ethics-ethics in broadcasting, to create a good impression results required precision in every editing process an information and the program. Thoroughness that is what makes some employees being stressed, because if there is the slightest error then the effect will be very long and affect the quality of news coverage. 
There are many ways to minimize or reduce the appearance of this stress; this research was obtained from several ways to slightly reduce the effect. Some of them are with sports, pray, play with friends, and even transmit their respective hobbies. For 10 employees NET Yogyakarta claimed to prefer chatting with friends for a bit to reduce stress. Although there are other things that are done as well playing, sports and even shopping. The activities were able to reduce the stress they feel, though not entirely disappear. Because, the next day in the office, then they should be prepared to get a new task is not impossible and would be a factor in the emergence of a new stress triggers.

\section{CONCLUSION}

Work in the world of television should be ready with all kinds of forms of risk, especially for working in representative offices. Although the quota area only $30 \%$ of the national broadcast (based on the broadcasting ACT), but still the preaching in the area became very important, and his work was not then reduced. The stress did indeed once again could not be avoided by any individual, whether it's working or not working.

\section{REFERENCES}

1. Creswell, J. W. (1994). Research Design Qualitative and Quantitative Approaches. Sage Publications. London.

2. Davis, K. \& Newstrom, J. W. (1989). Human Behavior at Work. 8th Edition. New York: Mcgraw-Hill

3. Davis, M. Eshelman, E. R., M'kay, M. (2008). The Relaxation And Stress Reduction Workbook (6th Edition). Oakland: New Harbinger Publications, Inc.

4. Feinstein, A., Owen, M. D. J. Dan Blair, N. (2002). A Hazardous Profession: War, Journalists, And Psychopathology. American Journal Psychiatry. 159, 1570- 1575.

5. Hidayat, F. \& Prakosa, H. (1997). Motivasi Berprestasi Dan Stres Kerja Wartawan Republika. Anima. 49, 50-57.

6. Lazarus, R. S. (1995). Psychological stress in the workplace. Occupational stress: A handbook, 1, 3-14.

7. Miles, M. B., Huberman, A. M., \& Saldana, J. (2013). Qualitative data analysis. Sage.

8. Patton, M. Q. (2005). Qualitative research. John Wiley \& Sons, Ltd.

9. Quick, J. C., Wright, T. A., Adkins, J. A., Nelson, D. L., \& Quick, J. D. (2013). Preventive stress management in organizations. American Psychological Association.

10. Severin, W. J., \& Tankard, J. W. (2001). Communication theories: Origins, methods, and uses in the mass media. Pearson College Division.

11. Smith, J. C. (2002). Stress Management: A Comprehensive Handbook Of Techniques And Strategies. New York: Springer Publishing Company, Inc.

12. Soewondo, S. (2010). Manajemen Stres Dengan Relaksasi Progresif. Depok: Tidak Diterbitkan.

13. Suls, J., \& Martin, R. (2005). The daily life of the garden-variety neurotic: Reactivity, stressor exposure, mood spillover, and maladaptive coping. Journal of personality, 73(6), 1485-1510.

14. Taylor, S. J., Bogdan, R., \& DeVault, M. (2015). Introduction to qualitative research methods: A guidebook and resource. John Wiley \& Sons.

15. Weiten, W., Lloyd, M. A., Dunn, D/ S., \& Hammer, E. Y. (2009). Psychology Applied To Modern Life: Adjustment In The 21st Century (9th Edition). California: Wadsworth Cengage Learning.

16. Zaenuddin, HM. (2007). The Journalist: Buku Basic Wartawan, Bacaan Wajib Para Wartawan, Editor, Dan Mahasiswa Jurnalistik. Jakarta. Prestasi Pustaka Publisher. 